\title{
Association of Cardiovascular Risk Factors and Metabolic Syndrome with Non-alcoholic and Alcoholic Fatty Liver Disease
}

\author{
A lum Han ( $\nabla$ qibosarang@naver.com ) \\ Wonkwang University Hospital
}

\section{Research article}

Keywords: non-alcoholic fatty liver, alcoholic fatty liver, cardiovascular risk factor, metabolic syndrome

Posted Date: December 2nd, 2020

DOI: https://doi.org/10.21203/rs.3.rs-117463/v1

License: (c) (1) This work is licensed under a Creative Commons Attribution 4.0 International License.

Read Full License 


\section{Abstract}

Background: This study aimed to evaluate differences between the incidence of cardiovascular risk factors and metabolic syndrome in non-alcoholic fatty liver disease (NAFLD) and alcoholic fatty liver disease (AFLD)

Methods: We compared the incidence of cardiovascular risk factors and metabolic syndrome between three groups of subjects $(n=913)$ : healthy, NAFLD, and AFLD groups. The healthy group had no liver disease. Drinking quantity for diagnosis was based on a previously accepted standard. Both the NAFLD and AFLD groups comprised patients with fatty liver disease diagnosed using computed tomography (CT). Metabolic syndrome risk was compared between the NAFLD and AFLD groups.

Results: No significant differences in several cardiovascular risk factors were observed between the NAFLD and AFLD groups. Upon analyzing the metabolic syndrome status in each group after making appropriate adjustments, the odds ratios (OR) in the NAFLD (OR $=2.397, \mathrm{P}=0.002)$ and AFLD groups (OR $=4.445, P=0.001$ ) were found to be significantly higher than that in the healthy group; the incidence rate of metabolic syndrome was similar in the NAFLD and AFLD groups.

Conclusion: Both the NAFLD and AFLD groups had more cardiovascular risk factors and higher metabolic syndrome risk than the healthy group. Thus, the prevention of fatty liver disease, regardless of the specific type, should involve the identification of cardiovascular and metabolic syndrome risk factors. If abdominal CT reveals a fatty liver, whether NAFLD or AFLD, the risk of cardiovascular disease and metabolic syndrome should be assessed.

\section{Background}

Fatty liver disease is defined as the accumulation of fat (mainly triglycerides [TG]) in hepatocytes that accounts for $>5 \%$ of the total liver weight. It includes benign steatosis and steatohepatitis, which can cause cirrhosis [1]. Fatty liver disease is largely divided into alcoholic (AFLD) and non-alcoholic fatty liver disease (NAFLD), depending on the drinking status of the patient. Distinguishing between the two types cannot be done clinically, biochemically, or by liver tissue biopsy, but only by determining the quantity of alcohol intake [1].

Fatty liver disease is diagnosed using imaging techniques such as ultrasonography, computed tomography (CT), and magnetic resonance imaging (MRI) [2]. Although the most accurate method for diagnosis is liver tissue biopsy, it is clinically difficult to perform. Therefore, assessment of the severity of fatty liver disease in clinical practice is mostly dependent on the clinical experience of the diagnosing physician [3]. For this reason, we evaluated cardiovascular risk factors and metabolic syndrome with fatty liver using CT rather than a liver tissue biopsy.

Alcoholic fatty liver is caused by excessive drinking. This is due to increased TG synthesis and increased influx of fatty acids from peripheral tissues into the liver during drinking, when the release of lipoproteins 
into the blood and the oxidation of fatty acids is poor [4]. While the condition can be alleviated by abstinence from alcohol, it can also progress to hepatitis, cirrhosis, and hepatocellular carcinoma [5]. Meanwhile, NAFLD has pathological characteristics similar to those of AFLD but occurs in nondrinkers and can progress to chronic liver diseases [6].

As the number of health screening examinees has been increasing in recent years, along with an increased interest in health, the number of people diagnosed with fatty liver disease has also increased. Patients should be informed of the risks associated with fatty liver disease, and the relationship of the disease with cardiovascular diseases, in order to help them understand the lifestyle changes needed to reduce risk factors, and should be provided with information about the treatment of this disease.

Obesity, diabetes, and hyperlipidemia are known factors that increase the risk of AFLD [7], which is known to increase the prevalence rate of metabolic syndrome and disorders [8, 9]. Although many studies on NAFLD are underway worldwide, and several existing studies have investigated the association between NAFLD and cardiovascular risk factors, studies comparing NAFLD and AFLD are scarce. Therefore, in this study, we investigated the morbidity rate of AFLD and NAFLD in male health-screening examinees, while assessing their pathological and behavioral characteristics. We performed a comparative analysis of the association between each cardiovascular risk indicator, and the differences between these indicators, by dividing the subjects into healthy, AFLD, and NAFLD groups.

\section{Methods}

\section{Study Subjects}

Study subjects were selected from among male and female city residents who underwent examinations at a university hospital health promotion center between March 2013 and March 2018. Based on the assumption of a significant difference in drinking habits between urban residents and the relatively fewer rural residents (Eop or Myon), the latter were excluded to keep the study conditions relatively homogeneous. The medical records of examinees who underwent CT were retrospectively reviewed in this study. Those who met the following criteria were also excluded from the study: incomplete records, leukocyte count $>10.0 \times 10^{3} / \mu \mathrm{L}$, acute hepatitis-related test findings, hepatitis B surface antigen (HBsAg) or hepatitis $\mathrm{C}$ virus antibody positive, abnormal thyroid function test findings, abdominal ultrasonography findings suggestive of diffuse or local liver diseases, creatinine level $>1.3 \mathrm{mg} / \mathrm{dL}$, or a history of cancer. In addition, those with hypertension, diabetes, rheumatoid arthritis, asthma, rhinitis, ischemic heart diseases and myocardial infarction, cerebral infarction and hemorrhage, and thyroid diseases, or those receiving hormone replacement therapy were also excluded. Participants with high-sensitivity C-reactive protein (hsCRP) levels $>10 \mathrm{mg} / \mathrm{dL}$ were excluded because they were suspected of having active inflammation or tissue damage, such as acute infection or systemic inflammation [10]. In addition, patients with normal abdominal ultrasonographic findings, but with aspartate aminotransferase (AST), alanine aminotransferase (ALT), and gamma-glutamyl transpeptidase (ख-GT) levels $>100 \mathrm{IU} / \mathrm{L}$ were excluded. As a result, 913 participants were included in the final analysis. This study followed the ethical standards 
laid out in the Declaration of Helsinki. The study was approved by the Clinical Trial Screening Committee of Wonkwang University Hospital (ARB approval number 201609-HR-097).

\section{Study Methods}

Through self-administered questionnaires and interviews with the attending physicians at the health promotion center, factors such as disease history, ongoing treatments and medications for existing diseases, drinking and smoking habits, and exercise habits were investigated. The types of alcohol and the average amount consumed per week were surveyed. By dividing the participants into current smokers and nonsmokers, the smoking status of the participants was also surveyed. The average weekly exercise frequency was also recorded.

\section{Anthropometric Measurements and Blood Pressure}

Height and weight were measured using an automatic height scale, and body mass index (BMI) was calculated by dividing weight by the square of height $\left(\mathrm{kg} / \mathrm{m}^{2}\right)$. Waist circumference was measured according to the level recommended by the World Health Organization at the middle (halfway) point between the lowest rib and iliac crest in the $\mathrm{CT}$ image. Blood pressure was measured using an automatic blood pressure monitor after maintaining stable pressure for $>10 \mathrm{~min}$, and the average of two measurements was recorded.

\section{Blood Tests}

Venous blood was collected at 10:00 AM, after more than $12 \mathrm{~h}$ of fasting. Fasting plasma glucose, total

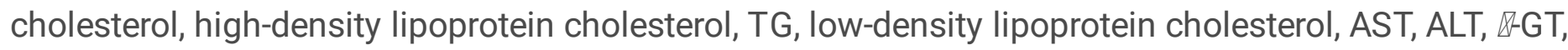
and hsCRP levels were measured.

\section{Abdominal CT}

Because abdominal CT results were obtained by several different medical imaging specialists, all of the data were reconfirmed by one medical imaging specialist to avoid examiner bias. CT examinations of the abdomen were performed using Somatom Definition (Siemens Medical Solutions, Forchheim, Germany). Steatosis was confirmed by either a liver attenuation $<40$ Hounsfield Units $(\mathrm{HU})$ or the liver attenuation was at least $10 \mathrm{HU}$ less than that of the spleen $[11,12]$.

\section{Classification of Study Groups}

The healthy group comprised examinees who showed normal liver echo in the abdominal CT; whose AST, ALT, and $\mathbb{R}$-GT values were normal in the liver function tests; and who drank alcohol at a rate of less than $140 \mathrm{~g} /$ week for men and $70 \mathrm{~g} /$ week for women [13]. The NAFLD group comprised examinees who were diagnosed with fatty liver disease according to abdominal CT results and drank less than $140 \mathrm{~g} /$ week for men and $70 \mathrm{~g} /$ week for women, regardless of the liver function test values $[14,15]$. Meanwhile, the AFLD 
group comprised participants who drank more than $140 \mathrm{~g} /$ week for men and $70 \mathrm{~g} /$ week for women and were not obese.

\section{Statistical Analysis}

SPSS for Windows version 26.0 (SPSS Inc., Chicago, IL, USA) was used for statistical analysis. A comparative analysis between non-continuous variables was performed using the chi-square test. The comparative analysis between continuous variables was performed using one-way ANOVA. The Scheffe test was used for post hoc testing of differences between groups. The analysis of covariance was used to analyze the average difference between the groups for the following factors: waist circumference, blood pressure, fasting plasma glucose, total cholesterol, high-density lipoprotein cholesterol, TG, lowdensity lipoprotein cholesterol, and hsCRP levels, after adjusting for age, BMI, daily smoking quantity, and weekly exercise frequency. The differences between the groups were confirmed using a simple and repeated method of contrast testing. The relationship between each group and the metabolic syndrome group was analyzed through multivariate logistic regression analysis after adjusting for age, daily smoking quantity, and weekly exercise frequency. Statistical significance was set at $P<0.05$.

\section{Results}

\section{General Patient Characteristics}

The average BMI was higher in the AFLD group than in both the NAFLD and healthy groups. Significant

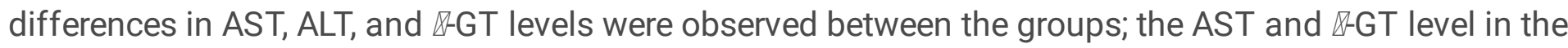
NAFLD group was higher than that in the healthy group. The ALT level was higher in the NAFLD and AFLD groups than in the healthy group. Both the AFLD and NAFLD groups had larger waist circumference than the healthy group, whereas no significant difference was found between the AFLD and NAFLD groups. Significant differences were found in the average weekly exercise frequency in the following decreasing order: the AFLD, healthy, and NAFLD group (Table 1). 
Table 1

Baseline characteristics of the study subjects

\begin{tabular}{|c|c|c|c|c|c|}
\hline Characteristic & $\begin{array}{l}\text { Healthy } \\
\text { (Group A) }\end{array}$ & $\begin{array}{l}\text { NAFLD } \\
\text { (Group B) }\end{array}$ & $\begin{array}{l}\text { AFLD } \\
\text { (Group C) }\end{array}$ & & \\
\hline Age (years) & $45.0 \pm 8.7$ & $43.6 \pm 8.0$ & $44.5 \pm 8.4$ & 0.003 & $b<a, c$ \\
\hline Total persons & $333(61.5)$ & $126(23.2)$ & $82(15.1)$ & ND & ND \\
\hline $\mathrm{BMI}\left(\mathrm{kg} / \mathrm{m}^{2}\right)$ & $23.2 \pm 2.4$ & $25.9 \pm 2.5$ & $24.2 \pm 2.7$ & $<0.0001$ & $a, b<c$ \\
\hline AST (IU/L) & $23.5 \pm 8.8$ & $26.6 \pm 10.4$ & $47.0 \pm 58.0$ & 0.002 & $a<b$ \\
\hline ALT (IU/L) & $25.7 \pm 14.0$ & $39.6 \pm 23.6$ & $31.4 \pm 16.9$ & $<0.0001$ & $a<b, c$ \\
\hline 『-GT (IU/L) & $45.2 \pm 52.5$ & $50.4 \pm 42.0$ & $79.8 \pm 68.4$ & 0.001 & $a<b$ \\
\hline Waist circumference $(\mathrm{cm})$ & $80.4 \pm 6.4$ & $86.4 \pm 7.5$ & $87.3 \pm 7.6$ & $<0.0001$ & $a<b, c$ \\
\hline \multicolumn{6}{|l|}{ Smoking status } \\
\hline None & $189(56.8)$ & $90(71.4)$ & $35(42.7)$ & \multirow{3}{*}{$<0.0001$} & \\
\hline Ex-smoker & $4(1.2)$ & $4(3.2)$ & $1(1.2)$ & & \\
\hline Smoker & $140(42.0)$ & $32(25.4)$ & $46(56.1)$ & & \\
\hline Exercise (frequency/week) & $1.4 \pm 1.6$ & $1.2 \pm 1.5$ & $1.2 \pm 1.5$ & 0.040 & $\mathrm{~b}<\mathrm{a}<\mathrm{c}$ \\
\hline \multicolumn{6}{|l|}{ Fatty liver grade } \\
\hline Mild & ND & $60(47.6)$ & $42(51.2)$ & & \\
\hline Moderate & ND & $52(41.3)$ & $37(45.1)$ & & \\
\hline Severe & ND & 14 (11.) & $3(3.7)$ & $<0.0001$ & \\
\hline \multicolumn{6}{|c|}{$\begin{array}{l}\text { Abbreviations: NAFLD, non-alcoholic fatty liver disease; AFLD, alcoholic fatty liver disease; BMI, body } \\
\text { mass index; AST, aspartate aminotransferase; ALT, alanine aminotransferase; } \mathbb{R}-G T \text {, gamma-glutamyl } \\
\text { transferase; ND, not done; NA, not available }\end{array}$} \\
\hline \multicolumn{6}{|c|}{ Data are presented as number (\%) or mean $\pm \mathrm{SD}$. } \\
\hline
\end{tabular}

\section{Comparison of Cardiovascular Risk Indicators}

Significant differences were found between the groups in terms of average systolic blood pressure, diastolic blood pressure, fasting plasma glucose level, total cholesterol level, TG level, high-density lipoprotein level, low-density lipoprotein level, and hsCRP level. In the comparative analysis between the 
groups through post hoc tests, no significant difference was found between the NAFLD and AFLD groups in terms of systolic blood pressure, diastolic blood pressure, fasting plasma glucose level, total cholesterol level, high-density lipoprotein level, TG level, low-density lipoprotein level, and hsCRP, but the values from either group were higher than those of the healthy group.

Systolic blood pressure was higher in the NAFLD group than in the healthy group, and the diastolic blood pressure was higher in the NAFLD and AFLD groups than in the healthy group. Fasting plasma glucose level was highest in the AFLD group, followed by the NAFLD group, and lowest in the healthy group. Highdensity cholesterol was lower in the NAFLD group than in the healthy group. TG levels were higher in the NAFLD and AFLD groups than in the healthy group. Low-density cholesterol was higher in the NAFLD group than in the healthy group. hsCRP level was higher in the AFLD group than in the healthy and NAFLD groups (Table 2). 
Table 2

Comparison between the cardiovascular risk factors according to the type of fatty liver

\begin{tabular}{|c|c|c|c|c|c|c|c|c|}
\hline $\begin{array}{l}\text { Cardiovascular } \\
\text { Risk Factor }\end{array}$ & $\begin{array}{l}\text { Healthy } \\
\text { (Group } \\
\text { A) }\end{array}$ & $\begin{array}{l}\text { NAFLD } \\
\text { (Group } \\
\text { B) }\end{array}$ & $\begin{array}{l}\text { AFLD } \\
\text { (Group } \\
\text { C) }\end{array}$ & $\mathbf{P a}^{a}$ & Scheffe & $\mathrm{P}^{\mathrm{b}}$ & $P^{c}$ & $P^{d}$ \\
\hline & & & & & & Avs.B & Avs.C & Bvs.C \\
\hline SBP $(\mathrm{mm} \mathrm{Hg})$ & $\begin{array}{l}121.3 \pm \\
12.6\end{array}$ & $\begin{array}{l}125.4 \pm \\
11.8\end{array}$ & $\begin{array}{l}124.5 \\
\pm 13.1\end{array}$ & $\begin{array}{l}< \\
0.0001\end{array}$ & $a<b$ & $\begin{array}{l}< \\
0.0001\end{array}$ & 0.242 & 0.909 \\
\hline DBP (mm Hg) & $\begin{array}{l}74.8 \pm \\
9.5\end{array}$ & $\begin{array}{l}78.4 \pm \\
10.2\end{array}$ & $\begin{array}{l}79.7 \pm \\
9.5\end{array}$ & $\begin{array}{l}< \\
0.0001\end{array}$ & $a<b, c$ & $\begin{array}{l}< \\
0.0001\end{array}$ & 0.005 & 0.691 \\
\hline glucose $(\mathrm{mg} / \mathrm{dL})$ & $\begin{array}{l}93 \pm \\
23.3\end{array}$ & $\begin{array}{l}97.5 \pm \\
25.9\end{array}$ & $\begin{array}{l}103.4 \\
\pm 25.9\end{array}$ & 0.002 & $a<b<c$ & 0.033 & 0.020 & 0.314 \\
\hline $\mathrm{TC}(\mathrm{mg} / \mathrm{dL})$ & $\begin{array}{l}199.4 \pm \\
35.2\end{array}$ & $\begin{array}{l}206.1 \pm \\
43.7\end{array}$ & $\begin{array}{l}207 \pm \\
41.9\end{array}$ & 0.037 & - & 0.056 & 0.434 & 0.987 \\
\hline $\mathrm{HDL}-\mathrm{C}(\mathrm{mg} / \mathrm{dL})$ & $\begin{array}{l}56.9 \pm \\
13.1\end{array}$ & $\begin{array}{l}53.9 \pm \\
14.4\end{array}$ & $\begin{array}{l}53.8 \pm \\
14.2\end{array}$ & 0.005 & $\mathrm{~b}<\mathrm{a}$ & 0.008 & 0.327 & 0.999 \\
\hline $\begin{array}{l}\text { TG } \\
(\mathrm{mg} / \mathrm{dL})\end{array}$ & $\begin{array}{l}101 \pm \\
64.8\end{array}$ & $\begin{array}{l}138.7 \pm \\
140.9\end{array}$ & $\begin{array}{l}147.4 \\
\pm 81.6\end{array}$ & $\begin{array}{l}< \\
0.0001\end{array}$ & $a<b, c$ & $\begin{array}{l}< \\
0.0001\end{array}$ & 0.008 & 0.852 \\
\hline LDL-C (mg/dL) & $\begin{array}{l}118.8 \pm \\
32.3\end{array}$ & $\begin{array}{l}125.5 \pm \\
38.1\end{array}$ & $\begin{array}{l}128.5 \\
\pm 38.3\end{array}$ & 0.009 & $a<b$ & 0.024 & 0.187 & 0.868 \\
\hline $\mathrm{hsCRP}(\mathrm{mg} / \mathrm{dL})$ & $\begin{array}{l}1.6 \pm \\
3.5\end{array}$ & $1.9 \pm 3.6$ & $\begin{array}{l}3.3 \pm \\
6.3\end{array}$ & 0.018 & $a, b<c$ & 0.576 & 0.021 & 0.087 \\
\hline
\end{tabular}

Abbreviations: NAFLD, non-alcoholic fatty liver disease; AFLD, alcoholic fatty liver disease; SBP, systolic blood pressure; DBP, fasting serum glucose, glucose; TC, total cholesterol; TG, triglyceride; DBP, diastolic blood pressure; HDL-C, high-density lipoprotein cholesterol; LDL-C, low-density lipoprotein cholesterol; hsCRP, high-sensitivity C-reactive protein; NA, not available. Data are presented as mean $\pm S D$ values.

aThe $P$ values were calculated using one-way ANOVA, and the post hoc test was performed using the Scheffe test.

${ }^{\mathrm{b}}$ The $\mathrm{P}$ values were calculated using the analysis of covariance after adjusting for age, body mass index, smoking quantity per day, and weekly exercise frequency per week.

${ }^{\mathrm{C}}$ The $\mathrm{P}$ values were calculated using the simple contrast test.

${ }^{\mathrm{d}}$ The $\mathrm{P}$ values were calculated using the repeated contrast test.

\section{Association with Metabolic Syndrome}


In the analysis to determine the association with metabolic syndrome status for each group after adjusting for age, smoking, and exercise frequency, the odds ratio (OR) in the NAFLD group $(O R=2.397$, $P=0.002)$ and $A F L D$ group $(O R=4.445, P=0.001)$ was significantly higher than that in the healthy group (Table 3), but no significant difference was found between the NAFLD and AFLD groups (Table 4).

Table 3

Relationship between the study subjects ${ }^{\mathrm{a}}$ and metabolic syndrome

\begin{tabular}{llll}
$\begin{array}{l}\text { Metabolic Syndrome } \\
\text { Variables }\end{array}$ & OR & P value $^{\text {b }}$ & 95\% Confidence Interval \\
Healthy & 1 & & \\
\hline NAFLD & 2.397 & 0.002 & $1.365-4.208$ \\
\hline AFLD & 4.445 & 0.001 & $1.792-11.022$
\end{tabular}

Abbreviations: NAFLD, non-alcoholic fatty liver disease; AFLD, alcoholic fatty liver disease; OR, odds ratio

${ }^{a}$ Adjusted for age, smoking quantity, and exercise frequency.

${ }^{\mathrm{b}}$ The $\mathrm{P}$ values were calculated using the multiple logistic regression test.

Table 4

Relationship between the type of fatty liver ${ }^{\mathrm{a}}$ and metabolic syndrome

Metabolic Syndrome $\quad$ OR $\quad$ P value $^{\mathrm{b}} \quad 95 \%$ Confidence Interval
Type of fatty liver

AFLD 1

$\begin{array}{llll}\text { NAFLD } & 0.565 & 0.226 & 0.225-1.423\end{array}$

Abbreviations: NAFLD, non-alcoholic fatty liver disease; AFLD, alcoholic fatty liver disease; OR, odds ratio

${ }^{a}$ Adjusted for age, smoking quantity, and exercise frequency.

${ }^{\mathrm{b}}$ The $\mathrm{P}$ values were calculated using the multiple logistic regression test.

\section{Discussion}

Fatty liver disease has the highest prevalence rate among liver diseases not only worldwide but also in South Korea. According to a recent study conducted in South Korea, the prevalence rate of fatty liver disease diagnosed using ultrasonography was $30 \%$, accounting for $69.7 \%$ of liver disease cases [16]. Similarly, the morbidity rate of fatty liver disease in this study was $32.3 \%$. The worldwide prevalence rate of NAFLD varies between studies [14]. In the US, one-third have been diagnosed with NAFLD, and in the 
UK it is reported as 29 cases per 100,000 person-years, which is clearly on a globally increasing trend [17, 18].

Because it is a standard commonly used in the diagnosis of NAFLD, the weekly alcohol consumption among patients diagnosed with NAFLD ranges from 0-140 $\mathrm{g}$ for men and $0-70 \mathrm{~g}$ for women $[14,15]$. In this study, we defined nondrinkers as individuals who consumed $<140 \mathrm{~g}$ per week, according to the standard proposed by Choi et al. [13]. In addition, while the total drinking quantity was measured through the questionnaire, $350 \mathrm{~mL}$ of beer, $120 \mathrm{~mL}$ of wine, $25 \mathrm{~mL}$ of brandy, or $50 \mathrm{~mL}$ of soju was considered to contain $10 \mathrm{~g}$ of alcohol by surveying the type of alcohol and the number of bottles consumed.

There was no difference between the NAFLD and AFLD groups for each of the indicators of cardiovascular risk factors. Importantly, however, these indicators differed between the two groups and the healthy group. This conclusion suggests that the risk factors are more related to the presence or absence of fatty liver, regardless of the cause of the occurrence of fatty liver. Systolic blood pressure, diastolic blood pressure, fasting plasma glucose level, total cholesterol level, and TG level were higher, whereas high-density cholesterol was lower in the NAFLD group than in the healthy group, indicating an increase in cardiovascular risk indicators in the NAFLD group. NAFLD is reportedly accompanied by obesity (30-100\%), diabetes (10-75\%), or dyslipidemia (20-92\%) [14]. In a study on the association between NAFLD and cardiovascular disease, blood pressure, fasting plasma glucose level, total cholesterol level, and TG level were higher in the NAFLD group than in the healthy group. In another study [19], systolic blood pressure, fasting plasma glucose level, total cholesterol level, and TG level were higher in the NAFLD group than in the healthy group, although sex-related differences in the values were found. The previous results are similar to the results of this study.

Diastolic blood pressure, fasting plasma glucose level, total cholesterol level, TG level, and hsCRP level were all higher in the AFLD group than in the healthy group. That is, except for high-density cholesterol levels, the values of the cardiovascular indicators in the AFLD group, as in the NAFLD group, were higher than those in the healthy group. Studies on the relationship between high-density cholesterol levels and fatty liver disease reported that high-density cholesterol levels were decreased in fatty liver [20, 21], though one study reported a contradictory result [22]. Additionally, other studies reported that low-density cholesterol levels were decreased in NAFLD $[23,24]$. In this study, low-density cholesterol levels were higher in the NAFLD group than in the healthy group. Several studies that investigated TG levels reported, as found in this study, that TG increased in both the NAFLD as well as AFLD groups [20-22, 25]. Although no difference was found in the hsCRP level, one of the cardiovascular risk indicators, in both the healthy and NAFLD groups, it was lower than that in the AFLD group. Among the many studies that support the association between fatty liver disease and inflammation indicators, one identified that high hsCRP levels were independently associated with fatty liver disease, obesity, and metabolic syndrome [25], whereas another reported that hsCRP level was a strong predictor of NAFLD [26].

While the metabolic syndrome rate was higher in the NAFLD and AFLD groups than in the healthy group, no significant difference was observed between the NAFLD and AFLD groups. A previous study reported 
that the fatty acid content in the liver was increased in patients with metabolic syndrome regardless of age, sex, or BMI [27], and an association between several metabolic disorders and serious liver diseases was identified $[28,29]$.

As for the limitations of this study, the study results cannot be generalized because all the patients included in the study were hospitalized at the same health promotion center. Moreover, achieving reliability was difficult because alcohol consumption level, smoking habit, and exercise frequency were surveyed through a self-administered questionnaire. In addition, NAFLD was determined by CT with no histologic confirmation of fatty liver. However, the fact that the AST/ALT ratio in most NAFLD patients was below 1 rationalizes the selection method of patients for the NAFLD group in this study [30].

This is a comparative study on not only NAFLD, which has been previously studied extensively, but also on AFLD, and patients taking medications for hypertension, diabetes, hyperlipidemia, ischemic heart disease, myocardial infarction, cerebral infarction, and hemorrhage were excluded. Therefore, this study is significant in that it provided a pure association between the cardiovascular risk indicators and the NAFLD or AFLD group.

\section{Conclusion}

The values of the cardiovascular risk indicators were significantly higher in the NAFLD and AFLD groups than in the healthy group in this study. Ultimately, considering that the patients in both the NAFLD and AFLD groups have the same cardiovascular disease risks, patients diagnosed with fatty liver disease should be examined for risk factors of cardiovascular diseases and should undergo management and treatment of such diseases. Although this study demonstrated that cardiovascular risk indicators and the severity of fatty liver are not associated, additional studies in this area are necessary.

\section{Abbreviations}

AFLD, alcoholic fatty liver disease; NAFLD, non-alcoholic fatty liver disease; CT, computed tomography; MRI, magnetic resonance imaging; HBsAg, hepatitis B surface antigen; hsCRP, high-sensitivity C-reactive protein; AST, aspartate aminotransferase; ALT, alanine aminotransferase; $₫$-GT gamma-glutamyl transpeptidase; BMI, body mass index; HU, Hounsfield Units; OR, odds ratio; TG, triglycerides

\section{Declarations}

\section{Ethics approval and consent to participate}

This study followed the ethical standards laid out in the Declaration of Helsinki. The study was approved by the Clinical Trial Screening Committee of Wonkwang University Hospital (IRB approval number 201609-HR-097). 
The name of IRB is Wonkwang University Hospital IRB, which belongs to Wonkwang University 3rd General Hospital, and its address is as follows: Wonkwang University Hospital, Sinyong-dong 344-2, Iksan, Jeollabuk-do

The consent was obtained by verbal from all participants. The reason is that we only reviewed patient charts for this study, we pledged that we would not use the information for anything other than research purposes. It was agreed by the Ethics Committee.

\section{Consent for publication}

Written informed consent for publication of their clinical details and/or clinical images was obtained from the patient/parent/guardian/ relative of the patient. A copy of the consent form is available for review by the Editor of this journal

\section{Availability of data and material}

Not applicable

\section{Competing interests}

The authors declare that they have no competing interests

\section{Funding}

This study was supported by Wonkwang University. When this manuscript is published, researchers receive a certain amount of research funding from Wonkwang University.

\section{Authors' contributions}

All authors read and approved the final manuscript

\section{Acknowledgements}

Not applicable

\section{References}

1. Bedogni G, Bellentani S. Fatty liver: how frequent is it and why? Ann Hepatol 2004;3(2):63-5. 
2. Van Hoek B. Non-alcoholic fatty liver disease: a brief review. Scand J Gastroenterol 2004;241(1 Suppl):56-9.

3. Sanyal AJ. Nonalcoholic steatohepatitis. Clin Perspect Gastroenterol 2000;3:129-139.

4. Crabb DW. Pathogenesis of alcoholic liver disease: newer mechanisms of injury. Keio J Med 1999;48: 184-8.

5. Sorensen TI, Orholm M, Bentsen KD, Hoybye G, Eghoje K, Christoffersen P. Prospective evaluation of alcohol abuse and alcoholic liver injury in men as predictors of development of cirrhosis. Lancet 1984;2: 241-4.

6. Yeon JE. The clinical implication of non-alcoholic fatty liver disease. J Korean Acad Fam Med 2003;24(6):510-5.

7. Seo SH, Lee HW, Park HW, Jang BG, Chung WJ, Park KS, et al. Prevalence and associated factors of nonalcoholic fatty liver disease in the health screen examinees. Korean J Med 2006;70(1):26-32.

8. Kang JH, Lee SW, Lee HS, Cho CY, Yu BY. The relation of nonalcoholic fatty liver disease to metabolic syndrome. J Korean Acad Fam Med 2004;25(10):746-53.

9. Lee SY, Kim SK, Kwon Cl, Kim MJ, Kang MS, Ko KH, et al. Clinical characteristics of health screen examinees with nonalcoholic fatty liver and normal liver function test. Korean J Gastroenterol 2008;52(3):161-70.

10. Gabay C, Kushner I. Acute-phase proteins and other systemic responses to inflammation. N Engl J Med 1999;340(6):448-54.

11. Lawrence DA, Oliva IB, Israel GM. Detection of Hepatic Steatosis on Contrast-Enhanced CT Images: Diagnostic Accuracy of Identification of Areas of Presumed Focal Fatty Sparing. Am J Roentgenol 2012;199(1):44-7. doi: 10.2214/AJR.11.7838

12. Chalasani N, Younossi Z, Lavine JE, et al. The diagnosis and management of non-alcoholic fatty liver disease: Practice Guideline by the American Association for the Study of Liver Diseases, American College of Gastroenterology, and the American Gastroenterological Association. Hepatology 2012;55(6):2005-23.

13. Choi SY, Kim D, Kang JH, Park MJ, Kim YS, Lim SH, et al. Nonalcoholic fatty liver disease as a risk factor of cardiovascular disease: relation of non-alcoholic fatty liver disease to carotid atherosclerosis. Korean J Hepatol 2008;14(1):77-88.

14. Angulo P. Nonalcoholic fatty liver disease. N Engl J Med 2002;346(16):1221-31.

15. Adams LA, Angulo P. Recent concepts in non-alcoholic fatty liver disease. Diabet Med 2005;22(9):1129-33.

16. Lee MY, Jung HR, Lim CH. Comparative analysis per area of the liver diseases in ultrasound diagnosis of healthcare center. J Korea Contents Assoc 2009;9(3):278-87.

17. Whalley S, Puvanachandra P, Desai A, Kennedy H. Hepatology outpatient service provision in secondary care: a study of liver disease incidence and resource costs. Clin Med 2007;7(2): 119-24.. 
18. Stepanova M, Younossi ZM. Independent association between nonalcoholic fatty liver disease and cardiovascular disease in the US population. Clin Gastroenterol Hepatol 2012;10(6):646-50.

19. Al Rifai M, Silverman MG, Nasir K, Budoff MJ, Blankstein R, Szklo M, et al. The association of nonalcoholic fatty liver disease, obesity, and metabolic syndrome, with systemic inflammation and subclinical atherosclerosis: the Multi-Ethnic Study of Atherosclerosis (MESA) Atherosclerosis. 2015;239:629-33. doi: 10.1016/j.atherosclerosis.2015.02.011.

20. Baraona E, Lieber CS. Effects of ethanol on lipid metabolism. J Lipid Res 1979;20(3):289-315.

21. Hannuksela ML, Rämet ME, Nissinen AE, Liisanantti MK, Savolainen MJ. Effects of ethanol on lipids and atherosclerosis. Pathophysiology 2004;10(2);93-103.

22. Turecky L, Kupcova V, Szantova M, Uhlikova E. Plasma lipid parameters in patients with alcoholic fatty liver after treatment with essential phospholipids. Bratisl Lek Listy 2003;104(7-8):227-31.

23. Ferrannini E, Balkau B, Coppack SW, Dekker JM, Mari A, Nolan J, et al. Insulin resistance, insulin response, and obesity as indicators of metabolic risk. J Clin Endocrinol Metab 2007;92(8):2885-92.

24. Targher G, Day CP, Bonora E. Risk of cardiovascular disease in patients with nonalcoholic fatty liver disease. N Engl J Med 2010;363(14):1341-50.

25. Riquelme A, Arrese M, Soza A, Morales A, Baudrand R, Perez-Ayuso RM, et al. Non-alcoholic fatty liver disease and its association with obesity, insulin resistance and increased serum levels of C-reactive protein in Hispanics. Liver Int 2009;29(1):82-8.

26. Yeniova AO, Küçükazman M, Ata N, Dal K, Kefeli A, Başyiğit S, et al. High-sensitivity C-reactive protein is a strong predictor of non-alcoholic fatty liver disease. Hepatogastroenterology 2014;61(130):4225 .

27. Kotronen A, Westerbacka J, Bergholm R, Pietiläinen $\mathrm{KH}$, Yki-Järvinen H. Liver fat in the metabolic syndrome. J Clin Endocrinol Metab 2007;92(9):3490-7.

28. Marchesini G, Bugianesi E, Forlani G, Cerrelli F, Lenzi M, Manini R, et al. Nonalcoholic fatty liver, steatohepatitis, and the metabolic syndrome. Hepatology 2003;37(4):917-23.

29. Marchesini G, Marzocchi R. Metabolic syndrome and NASH. Clin Liver Dis 2007;11(1):105-17.

30. Contos MJ, Sanyal AJ. The clinicopathologic spectrum and management of nonalcoholic fatty liver disease. Adv Anat Pathol 2002;9(1):37-51. 